\title{
Numerical study of a steel sub-frame in fire
}

\author{
Aldina Santiago $^{\mathrm{a}, *}$, Luís Simões da Silva ${ }^{\mathrm{a}}$, Paulo Vila Real ${ }^{\mathrm{b}}$, Milan Veljkovic ${ }^{\mathrm{c}}$ \\ ${ }^{a}$ Department of Civil Engineering, University of Coimbra, Polo II, Pinhal de Marrocos, 3030-290 Coimbra, Portugal \\ ${ }^{\mathrm{b}}$ Department of Civil Engineering, University of Aveiro, Portugal \\ ${ }^{\mathrm{c}}$ Department of Civil Engineering, Technical University of Luleå, Sweden
}

Received 28 May 2007; accepted 16 January 2008

Available online 10 March 2008

\begin{abstract}
Steel-framed buildings are generally designed with "simple" shear-resisting connections, and lateral forces are resisted by vertical bracing and shear walls. When a beam is considered then the effects of the longitudinal restraints by the adjacent structure and the rotational restraint by the connections has to be taken into account. Because of structural interaction, the beam behaviour at elevated temperature is rather complex.

This paper presents a numerical parametric study of a structural system consisting of an exposed steel beam restrained between a pair of fire protected steel columns. The structural sub-frame is modelled using 3D shell elements, thereby taking into account the effect of the local failure modes, and the realistic behaviour of the sub-frame exposed to natural fire. The numerical model accounts for the initial geometrical imperfections, nonlinear temperature gradient over the cross-section, geometrical and material nonlinearity and temperature dependent material properties.

Results obtained using a general Finite Element software - LUSAS and a fire dedicated software - SAFIR, are compared. The influence of following variables: beam span/depth ratio, lateral restraint, gradient temperature within the cross-section and mechanical load level is presented in the paper. The failure modes, the development of the internal forces and displacements throughout the analysis are considered to exemplify the effects of the variables considered.
\end{abstract}

(C) 2008 Elsevier Ltd. All rights reserved.

Keywords: Fire behaviour; Natural fire; Numerical modelling; Steel structures; Connections; Local and distortional buckling

\section{Introduction}

The behaviour of steel members during fire is complex and very much dependent on the restraint at the member ends. In order to capture the beam behaviour during a fire it is therefore required to take a global view and to examine the behaviour of a representative sub-structure [1] that can reproduce the redistribution of forces that takes place as the temperature varies with time. In steel structures, the restraint at member ends depends on the following two aspects: (i) the behaviour of the joints connecting, a beam

\footnotetext{
* Corresponding author. Tel.: +351 239 797257; fax: +351 239797217

E-mail addresses: aldina@dec.uc.pt (A. Santiago), luisss@dec.uc.pt (L.S.da Silva),pvreal@civil.ua.pt (P.V. Real), milan.veljkovic@1tu.se (M. Veljkovic).
}

to a column that is usually semi-rigid and/or partial strength and; (ii) the stiffness provided by the adjacent members (bending, axial or torsional stiffness).

Obtaining detailed experimental evidence of the behaviour of steel members subjected to realistic fire conditions is quite difficult and expensive. Natural fire tests, such as the Cardington tests [1] are of course ideal as they reproduce reality very closely but it is quite difficult to obtain detailed measurements of the mechanical response of individual members and to quantify the various parameters that control their behaviour. Available sub-frame tests are few and are usually unable to reproduce the transient temperature conditions that occur along the length of the members. It is therefore useful to develop numerical models to assess the behaviour of steel sub-frames subjected to fire.

Ideally, prescribed equations would be of greater interest for design purposes. However, the existing analytical 
approaches to include temperature effects (that change the mechanical properties of steel with temperature) such as Bradford et al. [2] are still of no practical interest because they are not able to incorporate key effects and are only valid in the elastic range (that in a fire event is only valid for the initial stage of the fire).

Steel sub-frames were studied in Huang et al. [3], Santiago et al. [4], Hao et al. [5]. The beam and columns are usually modelled by beam elements with the appropriate number of degrees of freedom, allowing in plane and outof-plane bending and shear deformation, while the joint behaviour is simulated by an assumed moment-rotation relationship. Large displacements are also required to reproduce catenary action. However, under fire conditions, large variable axial forces due to the restraint to thermal expansion during the heating phase and to thermal contraction during the cooling phase can be observed. This axial force, in combination with bending moment and shear force in the connection area induces local buckling and distortional buckling. Beam elements cannot realistically model local and distortional buckling; therefore, shell or solid elements should be used. Liu [6] and Lui and Davies [7] used a three-dimensional model created by isoparametric shell finite elements and beam-spring elements to model an internal bolted joint consisting of two identical cantilevers attached to a column. Comparisons against available tests results have shown good agreement. Yin and Wang [8] emphasized the effect of the axial and rotational restraints at the beam ends in the survival temperature in fire. They calibrated a numerical model against experimental results of fire tests on a restrained steel beam $[7,9]$ and carried out a parametric study on the parameters that affect the development of catenary action in a steel beam. Beam and end-plate were simulated by shell elements while the end restraints were modelled by elastic springs: axial restraint at the centroid of the beam and rotational restraints by two springs near the top and bottom of the beam. These studies were focused on the analysis of the influence of the joint and end restraints on the beam behaviour, specially force redistribution and displacements at high temperatures. Furthermore, with the exception of Santiago et al. [4], all used a "nominal" fire loading, constantly increasing temperature (ISO curve), so that the effect of the cooling phase was not considered. However, during the cooling phase the plastically deformed beam contracts significantly and some connection components experience tensile forces [10].

The main objective of this paper is to propose a threedimensional numerical model for a welded steel sub-frame using shell elements. The following phenomena are considered: the local failure modes; the influence of the heating and cooling phases and the response of the sub-structure; and the influence of several parameters relevant for the beam design. The main parameters are: temperature variation within the beam cross-section and along the beam, lateral torsional restraints on the top beam flange, beam span/ depth ratio and mechanical load factor. The study cases are
Table 1

Overview of the parametric study

\begin{tabular}{|c|c|}
\hline Parameter & Study cases \\
\hline $\begin{array}{l}\text { Gradient } \\
\text { temperature } \\
\text { within the beam } \\
\text { cross-section }\end{array}$ & $\begin{array}{l}\text { (i) Cardington beam temperature; (ii) large } \\
\text { temperature gradient within the cross-section; (iii) } \\
\text { uniform temperature within the cross-section }\end{array}$ \\
\hline $\begin{array}{l}\text { Gradient } \\
\text { temperature } \\
\text { along the beam } \\
\text { span }\end{array}$ & $\begin{array}{l}\text { (i) Cardington beam temperature along the beam } \\
\text { span; (ii) lower temperature on } 100 \mathrm{~mm} \text { from the } \\
\text { joint }\end{array}$ \\
\hline $\begin{array}{l}\text { Lateral-torsional } \\
\quad \text { restraint }\end{array}$ & $\begin{array}{l}\text { (i) top beam flange restrained; (ii) beam } \\
\text { unrestrained }\end{array}$ \\
\hline Beam length & $\begin{array}{l}\text { (i) } s p a n / \text { depth ratio }=19.3 \text {; (ii) } \mathrm{span} / \text { depth } \\
\text { ratio }=9.7 \text {; (iii) span/depth ratio }=14.5 \text {; (iii) span } / \\
\text { depth ratio }=29\end{array}$ \\
\hline $\begin{array}{l}\text { Mechanical load } \\
\text { factor }\end{array}$ & $\begin{array}{l}\text { (i) } P_{\mathrm{fid}}=12 \% P_{\mathrm{Rd}} ; \text { (ii) } P_{\mathrm{fi,d}}=20 \% P_{\mathrm{Rd}} ; \text { (iii) } \\
P_{\mathrm{fid}}=40 \% P_{\mathrm{Rd}} ;\left(\text { iv) } P_{\mathrm{fi,d}}=60 \% P_{\mathrm{Rd}} ;(\mathrm{v})\right. \\
P_{\mathrm{fid}}=80 \% P_{\mathrm{Rd}} \cdot P_{\mathrm{Rd}} \text { is the uniform distributed } \\
\text { loading corresponding to the design moment } \\
\text { resistance of the simple supported beam at room } \\
\text { temperature }\end{array}$ \\
\hline
\end{tabular}

listed in Table 1. The temperature results measured in the 7th Cardington fire test, Wald et al. [11], are considered.

\section{Numerical model}

\subsection{Introduction}

In order to explore the behaviour of a sub-frame steel system under fire loading, the structure of Fig. 1 was chosen. It consists of two HEA300 cross-section columns welded to an IPE300 cross-section beam with $5.7 \mathrm{~m}$ free span, supporting a $150 \mathrm{~mm}$ thick steel-concrete composite slab. The beam was assumed unprotected and the top flange unexposed to the fire load, while the column is thermally protected and unexposed to the fire load. This structural model corresponds to an experimental fire test programme carried out at the University of Coimbra in Portugal [12]. It also corresponds to a representative substructure of the 7 th Cardington fire compartment test $[11,13]$. The specification of the thermal loading (time-temperature-space variation) on the sub-structure was the measured transient temperatures.

As stated in Section 1, the degree of restraint at the beam ends is crucial for the redistribution of forces that takes place throughout the fire. It is thus useful to establish a non-dimensional measure of the restraint provided by the columns to the beam. The axial and rotational stiffnesses of the column at the beam level are given by:

$K_{\mathrm{a}}=\frac{3 E_{\mathrm{c}} \mathrm{I}_{\mathrm{c}}}{L_{\text {sup }}^{3}}+\frac{3 E_{\mathrm{c}} I_{\mathrm{c}}}{L_{\text {inf }}^{3}}=100715.6 \mathrm{kN} / \mathrm{m}$
$K_{\mathrm{r}}=\frac{3 E_{\mathrm{c}} I_{\mathrm{c}}}{L_{\text {sup }}}+\frac{3 E_{\mathrm{c}} I_{\mathrm{c}}}{L_{\text {inf }}}=174530.5 \mathrm{kN} / \mathrm{m}$ 


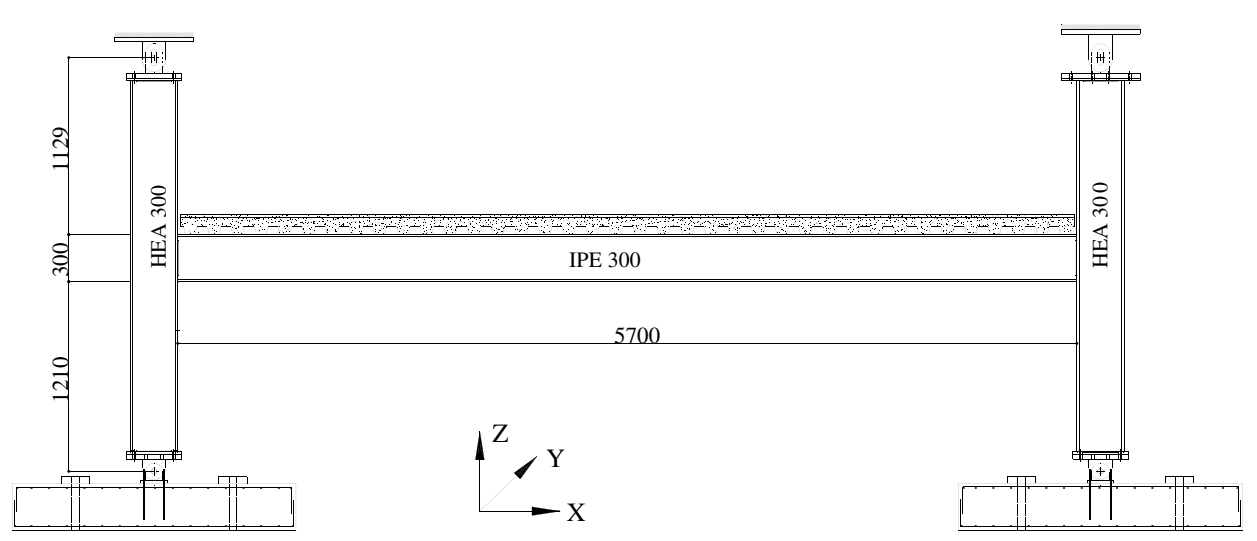

Fig. 1. Sub-structure model (mm).

where $E_{\mathrm{c}}$ is the Young modulus of the column, $I_{\mathrm{c}}$ the second moment of area of the column, $L_{\text {sup }}$ the upper length of the column and $L_{\text {inf }}$ the lower length of the column. The corresponding non-dimensional axial and rotational restraint ratios are given by:

$\beta_{\mathrm{a}}=\frac{K_{\mathrm{a}}}{E_{\mathrm{b}} \frac{A_{\mathrm{b}}}{L_{\mathrm{b}}}}=0.267$

$\beta_{\mathrm{r}}=\frac{K_{\mathrm{r}}}{4 \mathrm{E}_{\mathrm{b}} \frac{I_{\mathrm{b}}}{L_{\mathrm{b}}}}=7.460$

where $E_{\mathrm{b}}$ is the Young modulus of the beam, $I_{\mathrm{b}}$ the second moment of area of the beam, $A_{\mathrm{b}}$ the area of the beam and $L_{\mathrm{b}}$ the length of the beam.

In the following section, the implemented numerical model will be described in detail. The numerical model was modelled and calculated using the finite element code LUSAS [15].

\subsection{Material properties}

The assumed material of steel beam and columns at room temperature corresponds to the nominal law of S355. In order to perform a nonlinear geometrical analysis, this curve was modified to the true stress-logarithmic strain law as explained in Fig. 2. The steel is nonlinearly temperature dependent and therefore material properties, as given in EN 1993-1-2 [14], were used in the FE model. The effect

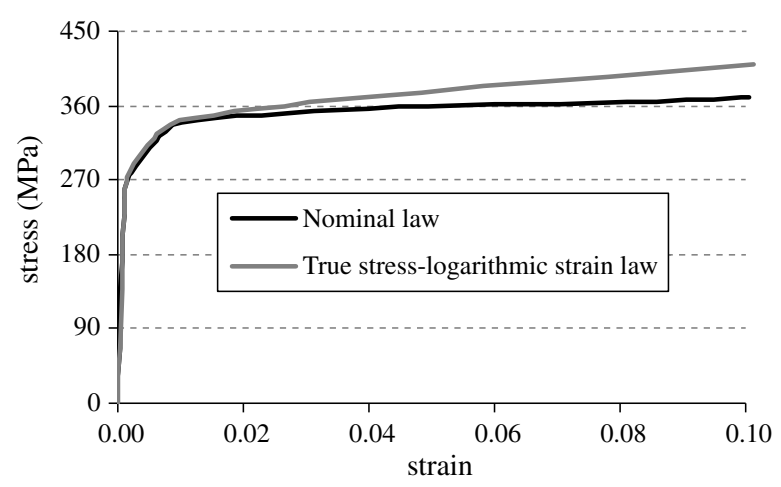

Fig. 2. Stress-strain relationship of steel at room temperature. of creep on the deformation of steel has been considered indirectly through the use of the conventional stressstrain-temperature relationship suggested by EN 1993-1-2.

\subsection{Finite elements and mesh discretization}

The numerical analysis was performed with the FE code LUSAS [15]. In order to reduce the model size and subsequent processing time, symmetry conditions were imposed at the beam mid-span. Three-dimensional eight-noded thick shell elements with five degrees of freedom per node $\left(u, v, w, \theta_{\alpha}, \theta_{\beta}\right)$ referred to the axes shown in Fig. 3 were employed. Its formulation accounts for shear, bending and membrane internal forces. The FE mesh depicted in Fig. 3 complies with the requirements for a reliable simulation and satisfies the mesh convergence study performed within the framework of this research work. This model has 2918 elements and 9068 nodes.

The concrete slab was not modelled as it only provided thermal boundary conditions for the temperature and lateral restraint to the beam top flange (non-composite behaviour).

\subsection{Imperfections}

In the beam, lateral geometrical imperfections were considered while the residual stresses were neglected. A lateral geometrical imperfection given by expression (5) was considered in accordance to prEN 1090-2:2007 [16] and Greiner [17]. An initial rotation around the $x$-axis with a maximum value of $L / 1000$ at mid-span and a curvature on the beam web with a maximum value of $4 \mathrm{~mm}$ at the mid-web were also introduced (Fig. 4).

$y(x)=\frac{L}{1000} \sin \left(\frac{\pi x}{L}\right)$

\subsection{Loading and boundary conditions}

Symmetry conditions were enforced at mid-span of the beam, the axial displacement in the $X$-direction was restrained as well as the rotations around the $Y$ and $Z$ 

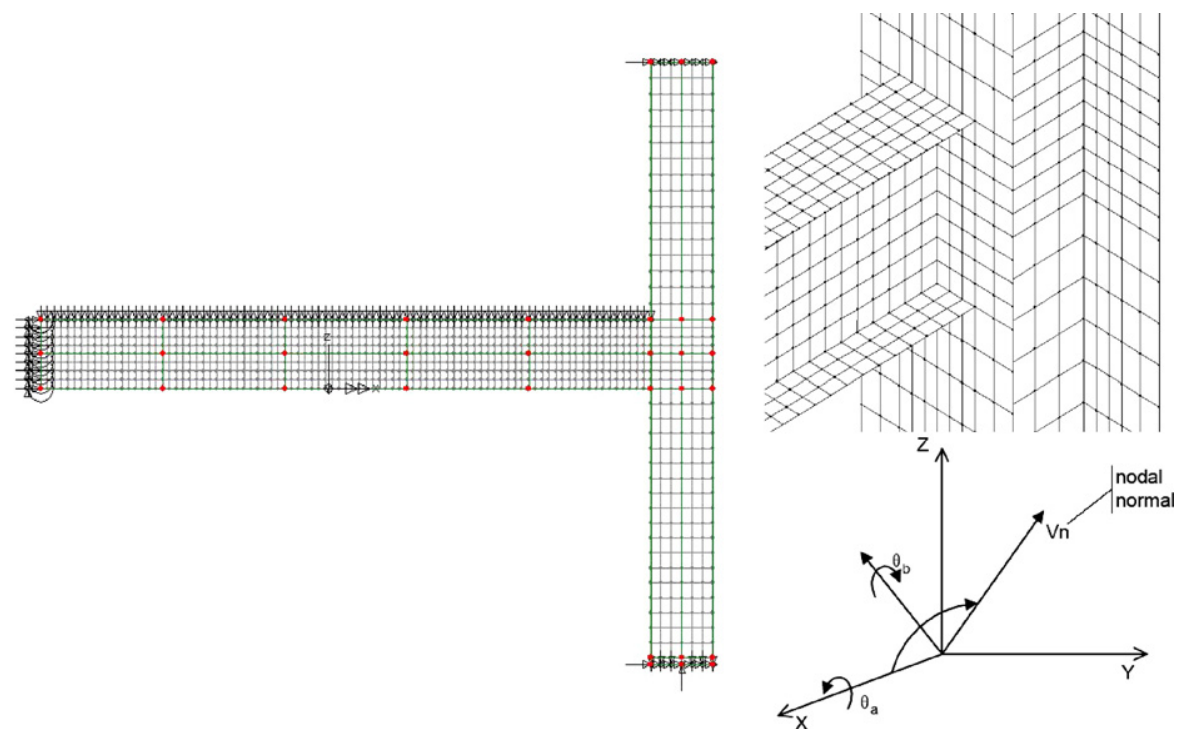

Fig. 3. Finite element model.

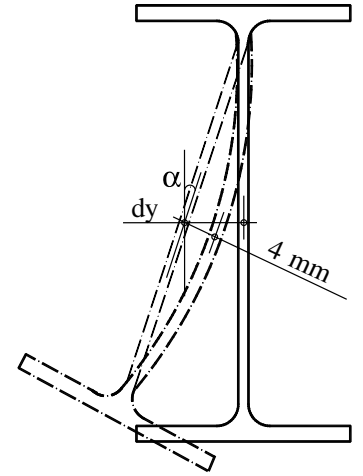

Fig. 4. Local geometric imperfection on the beam cross-section.

directions. Displacements in the $X, Y$ and $Z$ directions were restrained at the bottom of the column, while the top of the columns was only restrained in the $X$ and $Y$ directions. In the reference case it was considered that the beam was restrained by a concrete slab: displacement in the $Y$-direction was thus prevented at the top flange of the beam.

The mechanical loading applied at room temperature corresponds to the self-weight and a uniform loading of $10 \mathrm{kN} / \mathrm{m}$ distributed along the top flange of the beam, which corresponds to about $20 \%$ of the beam resistance at room temperature. This loading was applied at room temperature and remained constant throughout the analysis. The assumed thermal loading on the beam is shown in Fig. 5, and corresponds to a fire curve with heating and cooling phases that reproduces the beam mid-span temperatures observed during the 7 th Cardington fire test [11]. To avoid numerical convergence problems related to very low values of stiffness and yield stress of steel, slightly lower maximum temperatures than those observed experimentally were adopted (dotted line). Because the columns were fire protected they are assumed to remain at room temperature.

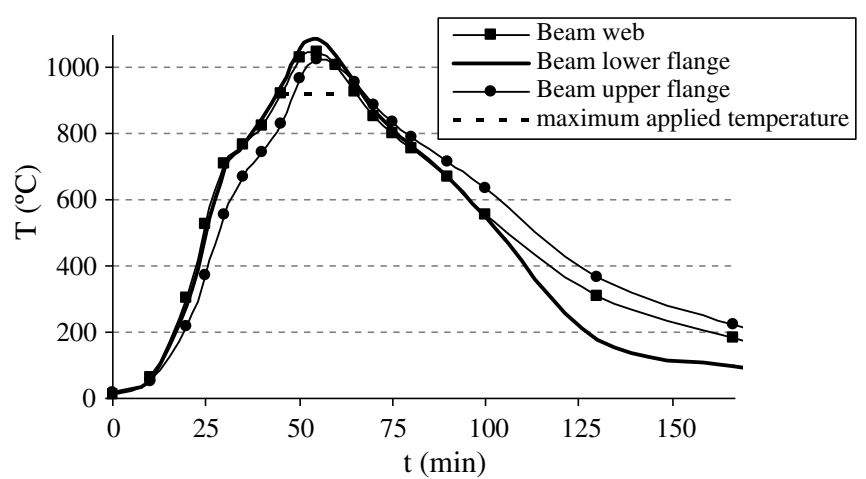

Fig. 5. Thermal loading.

\subsection{Nonlinear solution strategies}

The integration algorithm is of implicit type (implicit backward Euler), which ensures a quadratic convergence to the iteration procedure associated with the NewtonRaphson method. The kinematic description of shell elements in a nonlinear geometrical analysis is based on the Total Lagrangian formulation, which accounts for large displacements and small strains; in this formulation stresses and strains are output in terms of the "second Piola-Kirchoff stresses" and "Green Lagrange strains" with reference to the undeformed configuration. This requires the use of a true stress-logarithmic strain measure $\left(\sigma_{\mathrm{n}}-\varepsilon_{\mathrm{n}}\right)$ for the definition of the uniaxial material response, instead of the classic engineering constitutive law $(\sigma-\varepsilon)$ (Fig. 2). Both measures are related by the following relationship, Malvern [18]:

$\sigma_{\mathrm{n}}=\sigma(1+\varepsilon) \quad$ and $\quad \varepsilon_{\mathrm{n}}=\ln (1+\varepsilon)$

To account for the material nonlinearity, the von Mises yield criterion with nonlinear isotropic hardening was used. 
In the FE code LUSAS, the influence of the temperature on the elastoplastic response of the materials is represented in an approximate manner by calculating the elastic stresses using updated temperature dependent properties. The elastic predictor or trial stress $\sigma$ at time $t+\Delta t$ is evaluated in the following way:

(a) Elastically unloading the structure at time $t$, using the material modulus interpolated at temperature $\theta$, i.e.

$\sigma^{*}={ }^{t} \sigma-{ }^{t} D \cdot{ }^{t} \varepsilon^{\mathrm{e}} \quad$ where ${ }^{t} \varepsilon^{\mathrm{e}}={ }^{t} \varepsilon-{ }^{t} \varepsilon^{\mathrm{p}}$

(b) Elastically re-loading the structure at time $t+\Delta t$, using the material modulus interpolated at temperature $\theta^{t+\Delta t}$, i.e.

${ }^{t+\Delta t} \sigma=\sigma^{*}+{ }^{t+\Delta t} D\left({ }^{t} \varepsilon^{\mathrm{e}}+\Delta \varepsilon\right) \quad$ where $\Delta \varepsilon={ }^{t+\Delta t} \varepsilon-{ }^{t} \varepsilon$

where ${ }^{t} \sigma$ is the stress at time $t,{ }^{t} D$ and ${ }^{t+\Delta t} D$ are the stiffness matrices at time $t$ and $t+\Delta t$, respectively, and ${ }^{t} \varepsilon$ and ${ }^{t+\Delta t} \varepsilon$ are the strains at time $t$ and $t+\Delta t$, respectively.

\subsection{Failure criteria}

In order to assess the occurrence of failure throughout the fire event, a failure criteria is required. The failure conditions can be established by assuming that cracking occurs when the ultimate strain $\varepsilon_{\mathrm{u}}$ is attained. The failure should be assessed by comparing the maximum equivalent strain $\varepsilon_{E \text { max }}$ with $\varepsilon_{\mathrm{u}}$. Literature indicates that at high temperatures, the ultimate strain for high strength bolts is about $1-6 \%$, Li et al. [19], and for constructional steel, ultimate strains of 20\% may be expected EN 1993-1-2 [14].

\section{Reference case: behaviour and validation of the numerical model}

\subsection{Introduction}

To provide the basis for the various parametric studies, a reference case was established. It consists of the structural model of Fig. 1. With respect to Table 1, it corresponds to:

(i) gradient temperature within the cross-section that corresponds to the Cardington temperature at the beam mid-span. Gradient temperature along the beam span was not considered;

(ii) top flange of the beam continuously restrained;

(iii) a span/depth ratio of 19.3 , corresponding to a free span of $L_{0}=5700 \mathrm{~mm}$;

(iii) a mechanical load factor $P_{\mathrm{fi}, \mathrm{d}}=20 \% P_{\mathrm{Rd}}$.

Because of the complexity of performing a transient temperature nonlinear numerical analysis of a steel structure with temperature varying material properties, this reference case was analyzed using two different FE programs. LUSAS [15], a general purpose commercial nonlinear finite element code was used throughout this study, while SAFIR
[20], a specialized finite element code specifically developed for the analysis of structures subjected to fire was only used for the reference case, to provide additional validation of the numerical results.

In the case of LUSAS, all calculations were carried out using shell elements, as it was already described in Section 2.3, while for SAFIR two alternative analyses were performed using beam and shell elements.

\subsection{Global behaviour}

Fig. 6 illustrates the variation of the mid-span deflections of the beam throughout the fire, for the three FE models. For all cases, this variation is markedly different during the analysis. It starts gradually but, as the lower beam flange temperature rises above $550{ }^{\circ} \mathrm{C}(t=25 \mathrm{~min})$, the rate of deformation increases significantly. At the maximum temperature, the mid-span deflection was about $0.34 \mathrm{~m}$, corresponding to $L / 8, L / 20$ being the usual maximum deflection at the fire limit state, BS 476 [21]. During the cooling phase, since the material has been stressed beyond the elastic limit, the corresponding strain does not follow the same stress-strain path as during the heating phase and a plastic deflection is observed: $0.27 \mathrm{~m}$.

It is noted that the analysis using beam elements is unable to follow the cooling phase, the model becoming numerically unstable before reaching the maximum temperature. Both analyses using shell elements show good agreement.

Fig. 7 illustrates the development of the axial force and bending moment at mid-span of the beam (cross-section A) and at a cross-section $0.03 \mathrm{~m}$ away from the column flange - cross-section B. For the shell models, the axial force was calculated by equilibrium and by the integration of the normal stresses at the cross-section B while the bending moment is always calculated by taking moments with respect to the beam bottom flange axis.

The analysis of the development of the internal forces should be divided into different stages. In Phase 1 $(t<9 \mathrm{~min})$ the thermal expansion was converted into thermal stresses that increased the level of axial compression and sagging moment without large displacements (Fig. 6). Phase 2 that starts approximately after $9 \mathrm{~min}$ of the fire exposure, corresponds to the increase of the

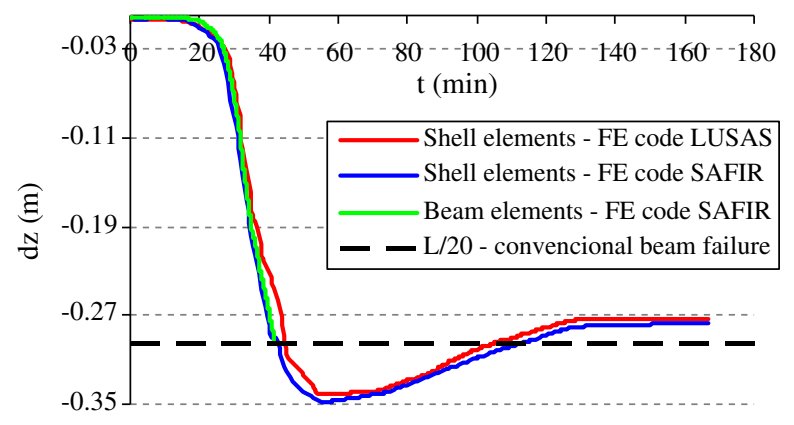

Fig. 6. Development of the mid-span deflection during the fire. 

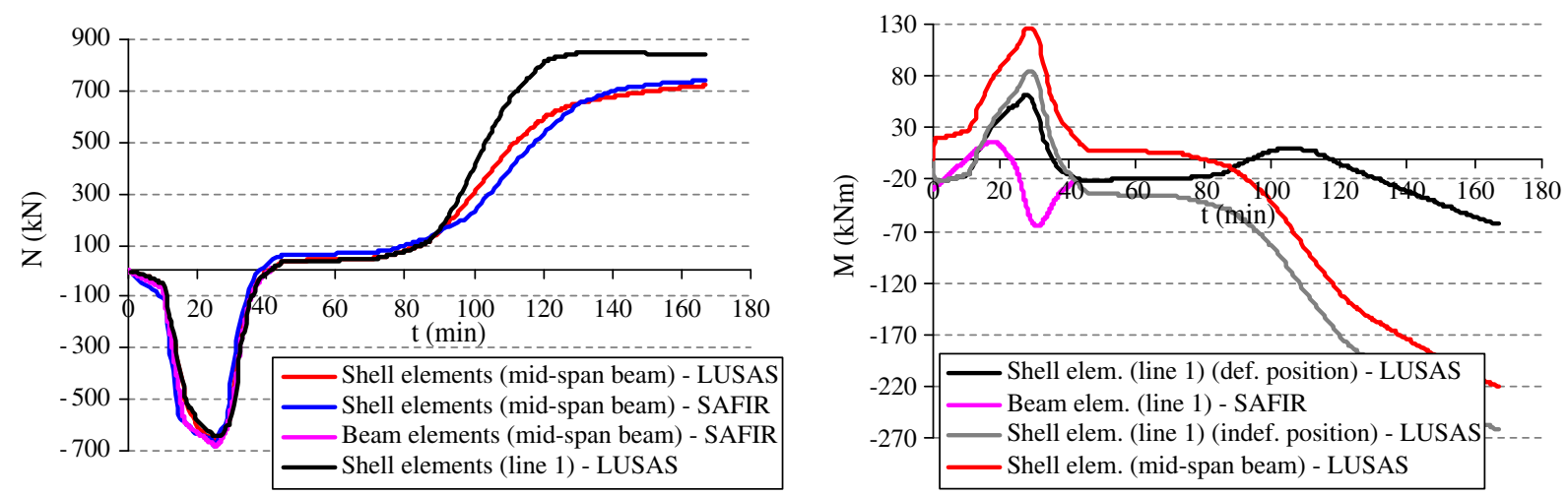

Fig. 7. Development of the beam axial force and bending moment during the fire.

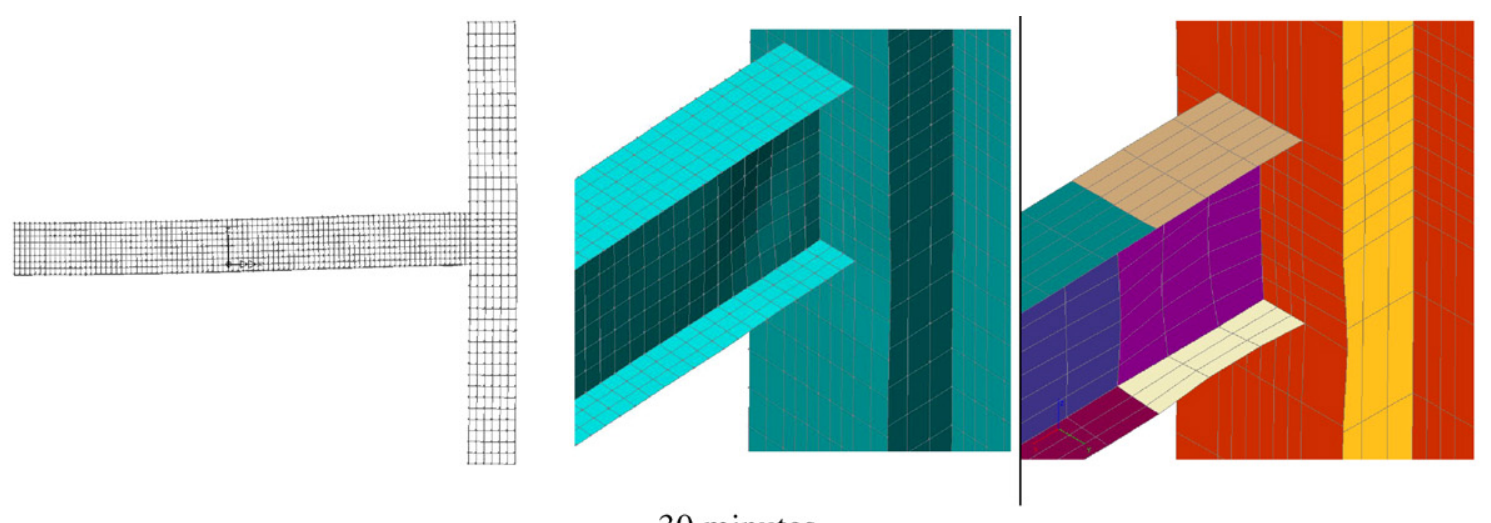

30 minutes

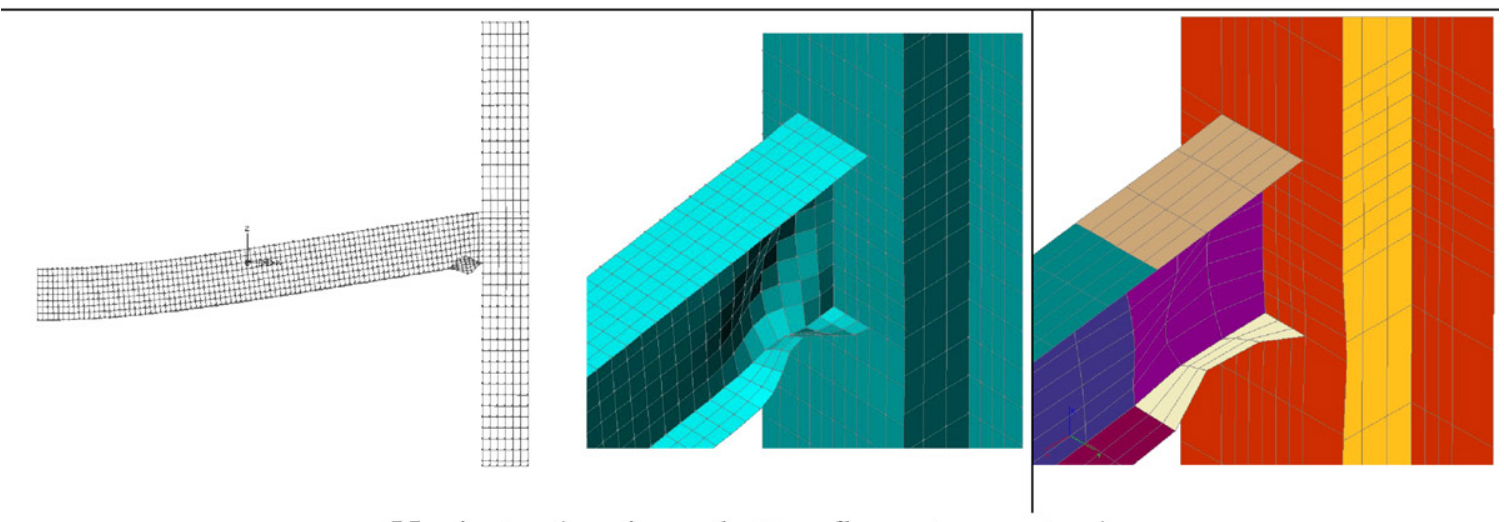

55 minutes (maximum bottom flange temperature)

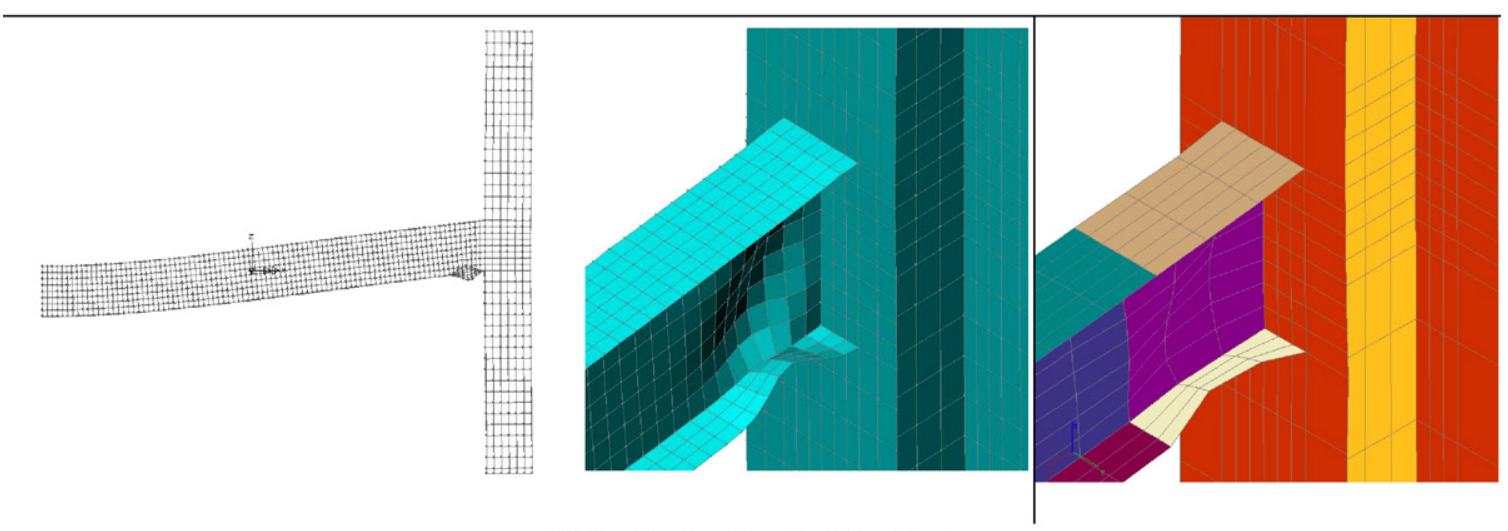

167 minutes (end of the fire)

Fig. 8. Deformed mesh (LUSAS - left side; SAFIR - right side). Scale factor is 1.0. 
internal forces. In Phase 3 ( $26 \mathrm{~min}<t<45 \mathrm{~min}$ ) a decrease of the internal forces is noted because of the material strength degradation and large deflections. In Phase 4 (45 $\mathrm{min}<t<55 \mathrm{~min}$ ), the beam behaviour changes from bending to catenary action and tensile forces are developed. Bending moments reduce and become similar to those observed at room temperature. Phase $5(t<55 \mathrm{~min})$ corresponds to the cooling phase - increasing of the tensile forces and hogging moment because of the recovering of strength and stiffness. At about $t=125 \mathrm{~min}$, because the cooling rate reduces and the beam reaches temperatures lower than $400{ }^{\circ} \mathrm{C}$, and the bottom flange temperature is lower than $200{ }^{\circ} \mathrm{C}$, the rate of development of the mid-span deflection and internal forces also decrease. It is finally noted that during cooling the axial force is not constant along the beam.

\subsection{Local behaviour at the joints}

Fig. 8 shows the evolution of deformation with time around the joint area. Local buckling of the beam bottom flange and shear buckling at the web in the vicinity of the joint were the main failure mechanisms. This local buckling occurs during the heating phase after about $30 \mathrm{~min}$ of fire, due to the restraint to thermal elongation provided by the adjacent cooler column. The heated bottom flange of the
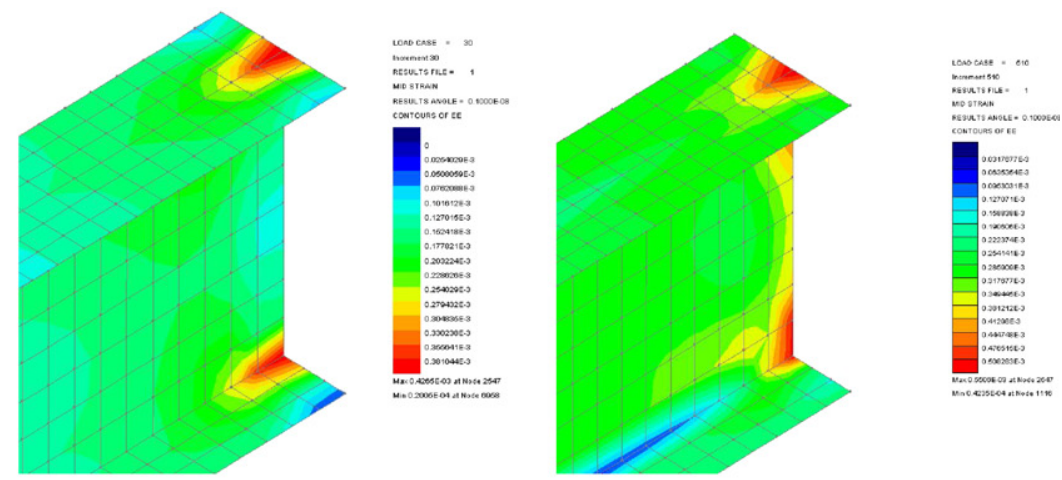

$$
t=0.5 \min .\left(\varepsilon_{\mathrm{Emax}}=0.39 \mathrm{E}-3\right)
$$

$$
t=8.5 \min .\left(\varepsilon_{\mathrm{E} \max }=0.47 \mathrm{E}-3\right)
$$
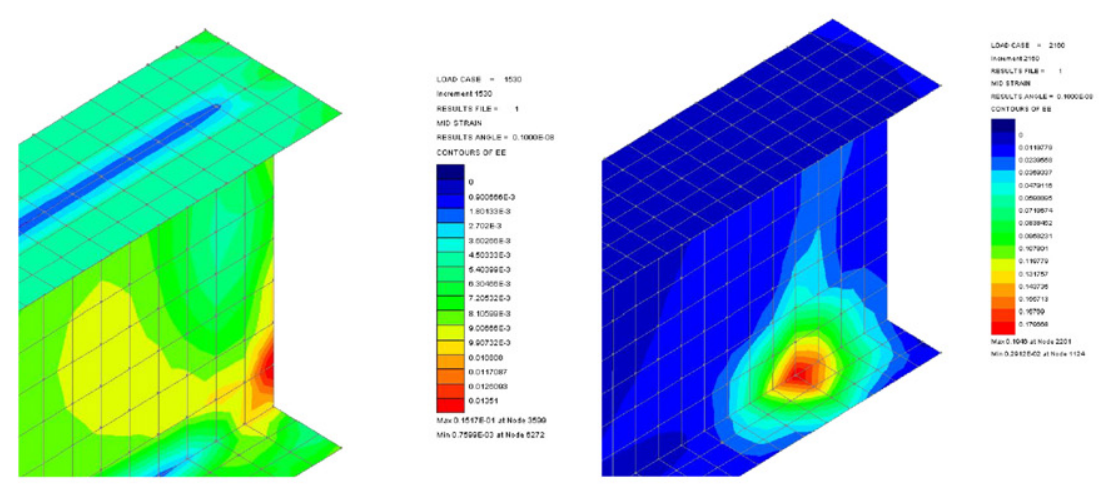

$$
t=26 \min .\left(\varepsilon_{\mathrm{Emax}}=0.015\right)
$$

$$
t=36 \min .\left(\varepsilon_{\mathrm{Emax}}=0.19\right)
$$
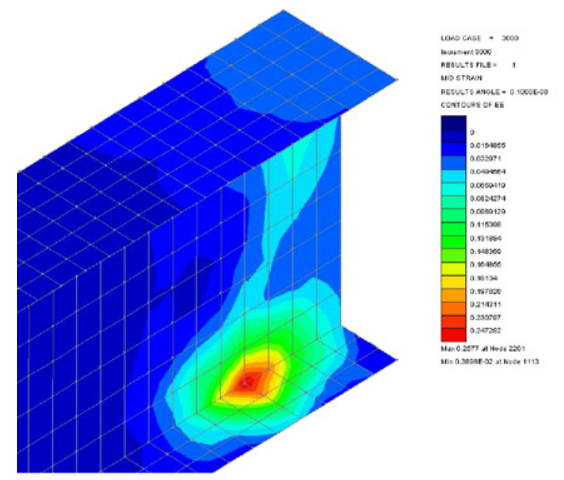

$$
t=50 \min .\left(\varepsilon_{\mathrm{Emax}}=0.27\right)
$$

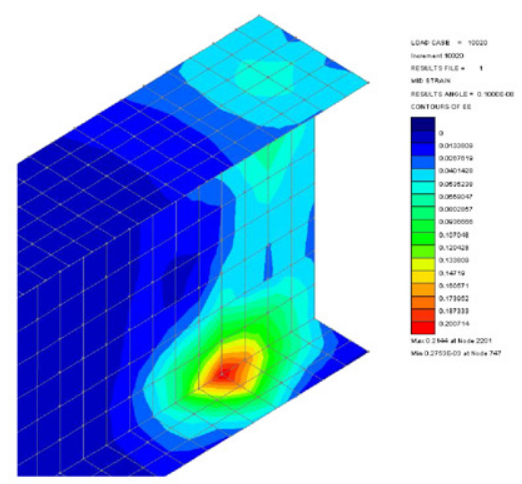

$$
t=166 \min .\left(\varepsilon_{\operatorname{Emax}}=0.21\right)
$$

Fig. 9. Development of the maximum equivalent strains in the beam near the connection. 
beam is insufficient to transmit to the column the high normal forces generated by the thermal stresses; subsequently, these forces are partially transferred to the heated web, that is also unable to transfer them to the column and buckling is developed. The beam could be assumed to behave as 'simply supported', allowing larger mid-span deflections to develop (Fig. 6).

Fig. 9 shows the development of the equivalent strains, $\varepsilon_{\mathrm{E}}[22]$ in the vicinity of the joint. Fig. 10 depicts the corresponding axial forces, as well as the beginning of the yielding at each beam zone ${ }^{t} \sigma_{\mathrm{E}} \geqslant{ }^{t} f_{\mathrm{y}}$; where ${ }^{t} \sigma_{\mathrm{E}}$ and ${ }^{t} f_{\mathrm{y}}$ are the equivalent stress and the yield stress at time $t$. Also for the joint behaviour distinct phases during the fire can be identified: before the start of the fire, uniform tensile and compressive bands along the alignment of the top and bottom flanges of the beam are present, due to the mechanical loading. On the web panel a state of almost pure shear is observed. These stresses and strains on the top and bottom flanges of the beam are mechanical strains. As the temperature starts to increase (phase 1), thermal strains are also introduced (positive strains) that increase the total strain in the top flange and decrease it in the bottom flange $(t=9 \mathrm{~min}$.). Some of these thermal strains are converted into stresses which increase the axial compressive force. Beyond a temperature of $100{ }^{\circ} \mathrm{C}$ (phase 2), the elastic modulus reduces with temperature and the mechanical strains also increase. Beyond $400{ }^{\circ} \mathrm{C}$ (phases 3 and 4), total strains continue to increase. In the joint these strains are converted in stresses; however, due to the reduction of the yield stress with temperature, stresses on the beam decrease. Due to the high stiffness of the column, that remains at room temperature, and the local massivity of the joint compared with the beam, the high strains observed on the beam bottom flange move way from the joint $-100-110 \mathrm{~mm}$ (26 min). The maximum value of the equivalent strain is $\varepsilon_{\mathrm{E}}=27 \%$ and it is observed in the interface bottom flange - web at $t=50 \mathrm{~min}\left(\theta_{\text {bottom flange }}=890^{\circ} \mathrm{C}\right)$. Theses high strains induce the local buckling observed in Fig. 8. At these high temperatures, the bottom flange has low compressive strength, the band of stresses and strains spreads up to the web and shear buckling in the web is also observed. Once the cooling phase starts (phase 5) the ther-

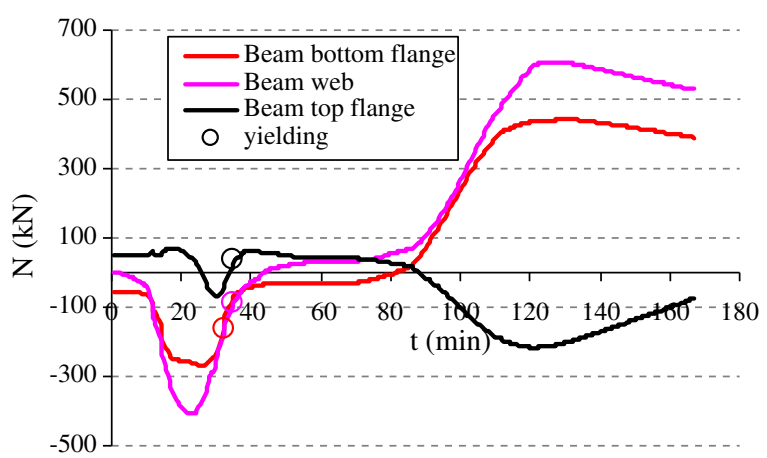

Fig. 10. Axial forces developed in the beam at $0.03 \mathrm{~m}$ from the column flange (cross-section B). mal strains begin to reduce. This induces a reversal of the deflection (Fig. 6) generating tensile axial forces in the web and bottom flange and compressive axial forces in the top flange (166 min).

\section{Influence of the beam span-to-depth ratio}

In order to assess the influence of the beam span-todepth ratio, four different spans were considered for the sub-structure model of Fig. 1: $2850 \mathrm{~mm}, 4275 \mathrm{~mm}$, $5700 \mathrm{~mm}$ and $8550 \mathrm{~mm}$, corresponding to $50 \%, 75 \%$, $100 \%$ and $150 \%$ of the span of the reference case $\left(L_{0}\right)$. Given that the cross-section of the beam is kept constant (IPE300), the corresponding span-to-depth ratios vary between 9.7 and 29 , representing a range that is fairly typical of practical designs. For consistency, the mechanical load level on the beams was adjusted to give a constant load ratio of $P_{\mathrm{fi}, \mathrm{d}}=20 \% P_{\mathrm{Rd}}$. Table 2 lists the resulting uniformly distributed loads, together with the corresponding axial and rotational restraint ratios.

For the longer beam spans, the failure mode is similar to the observed for the reference case. For the short beam spans, low bending and axial deformations are observed and large compressive deformations in the web and bottom flange are developed.

Fig. 11 shows that when the beam behaviour is controlled by bending at low temperatures, a longer beam span gives larger beam deflections. At high temperatures, when the beam behaviour is controlled by catenary action, all beam deflections converge ( $45 \mathrm{~min}$ ), except for $L=1.5 L_{0}$, due to the previous large deflections that already occurred at low temperatures. During the cooling phase, the rate of recovery is dependent on the beam span. Long beam spans show the highest rate of deflection reduction.

Table 2

Beam span-to-depth ration: study cases

\begin{tabular}{llllllr}
\hline$L / L_{0}$ & $L$ & Span/depth & $P_{\mathrm{fi}, \mathrm{d}}(\%)$ & $P(\mathrm{kN} / \mathrm{m})$ & $\beta_{\mathrm{a}}$ & \multicolumn{1}{c}{$\beta_{\mathrm{r}}$} \\
\hline 0.5 & 2850 & 9.7 & 20 & 40.0 & 0.125 & 3.55 \\
0.75 & 4000 & 14.5 & 20 & 17.8 & 0.180 & 4.98 \\
1.0 & 5700 & 19.3 & 20 & 10.0 & 0.265 & 7.46 \\
1.5 & 8550 & 29 & 20 & 4.44 & 0.380 & 10.63 \\
\hline
\end{tabular}

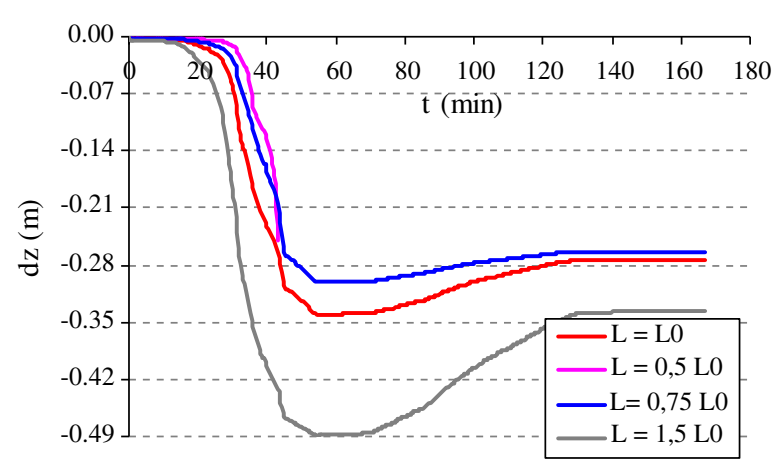

Fig. 11. Development of the mid-span deflection during the fire. 


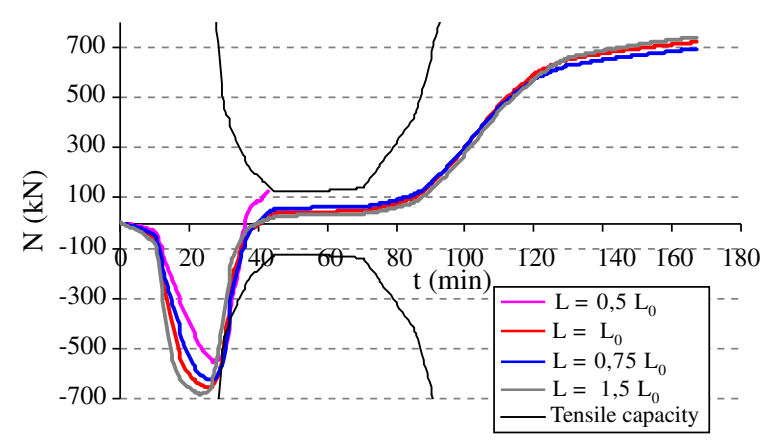

Fig. 12. Development of the beam axial force during the fire.

At low temperatures, the compression force varies with the beam span, due to different rate of thermal expansion (Fig. 12). As the temperature increases and the axial stiffness decreases, this different rate is more noticeable. Long beams have higher compression forces. The compression force starts to drop at a slightly lower temperature for the longer beam spans, but the start of the decrease of compression displacement is independent of the beam span. At high temperatures, because the beams have the same crosssectional area, they behave similarly and have almost the same catenary force, indicating a minor influence of the beam bending resistance. The tensile axial force is independent of the beam span during the cooling phase. In all cases, the axial forces are within the bounds corresponding to the tensile capacity [14], but in the case $L=0.5 L_{0}$, the

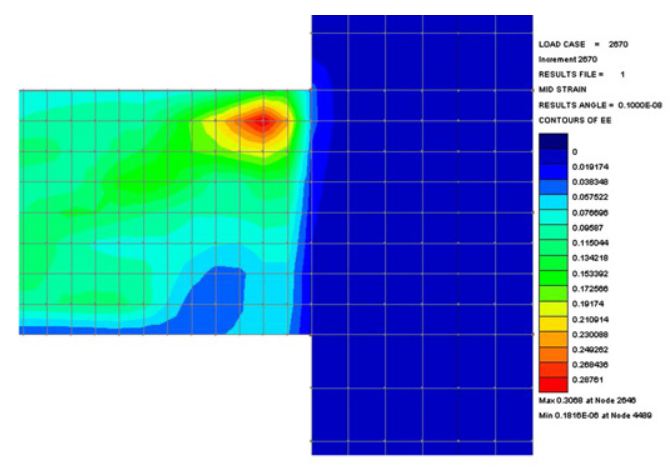

$0.5 L-\mathrm{t}=45 \min .\left(\varepsilon_{\text {Efail }}=0.31\right)$

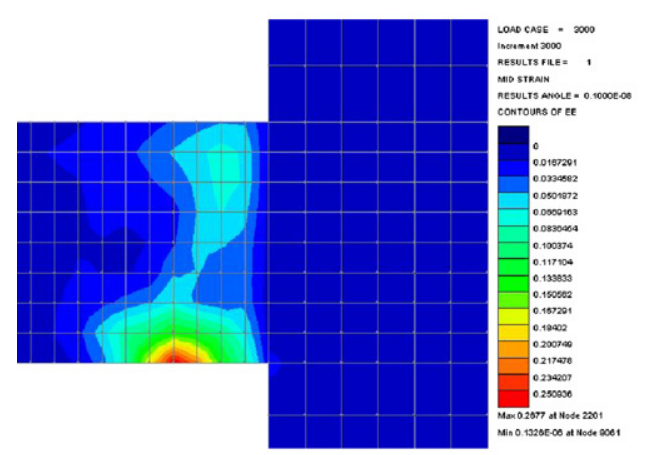

$1.0 L-t=50 \mathrm{~min} .\left(\varepsilon_{\mathrm{Emax}}=0.27\right)$ beam fails when the maximum catenary force reaches the tensile capacity.

Fig. 13 shows that for the short beams, the maximum equivalent strains near the joint are located at the top of the cross-section. However, as the beam span increases, the maximum equivalent strains decrease and shifts towards the bottom beam flange.

\section{Influence of temperature gradient within the beam cross- section}

Gradient temperature within the beam cross-section is usually the result of the heat sink effect of the concrete slab on the top flange. Special reference on the study of the temperature gradient effect within the beam cross-section on the structural behaviour is made to Yin and Wang [8] that demonstrate that the temperature gradient has a small influence on the development of the catenary action at high temperatures. In the following, the temperature gradient effect on the local joint behaviour is discussed. The results for the reference case (case a) are compared with two other different cases (Fig. 14):

(i) Case b: uniform temperature within the beam crosssection that corresponds to the bottom beam flange temperature of the reference case; and

(ii) Case c: large gradient temperature, the bottom flange and web having the same temperature as the reference case but the top flange temperature is reduced.
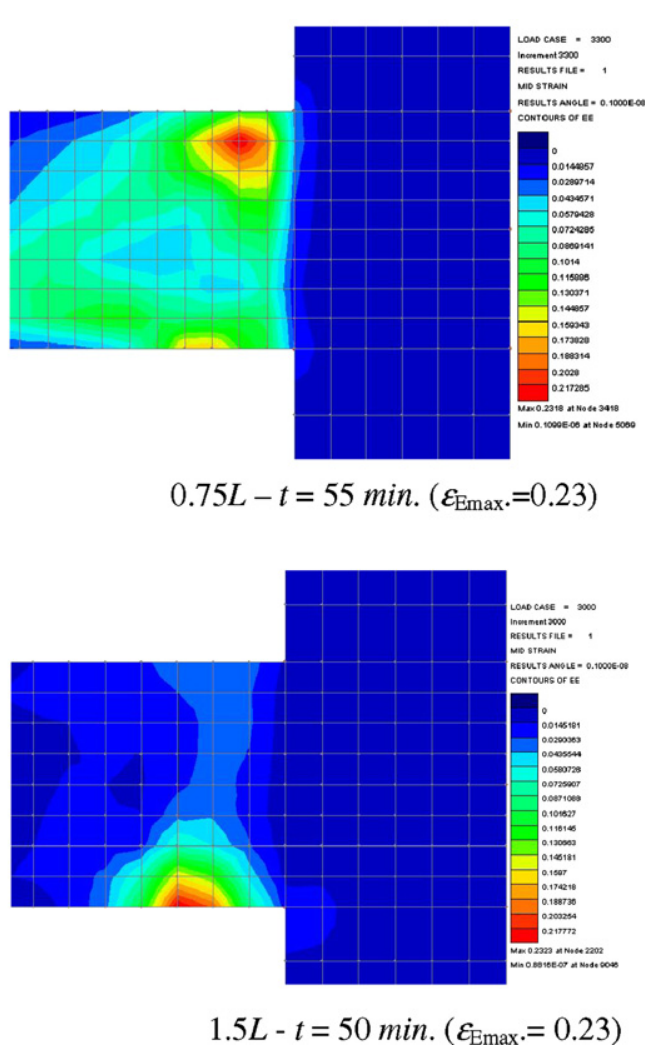

Fig. 13. Development of the maximum equivalent strains in the joint. 

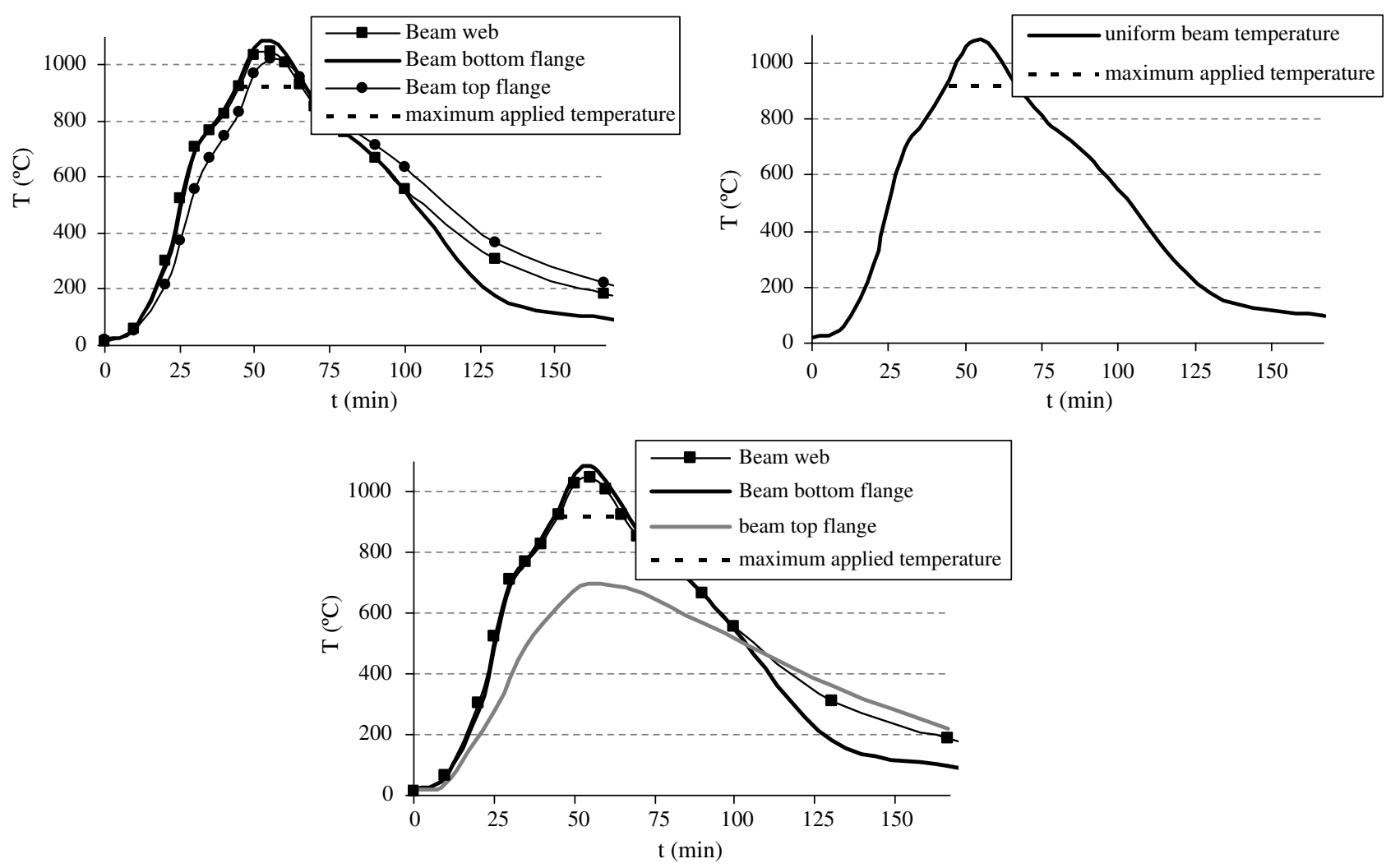

Fig. 14. Thermal loading: (a) reference case; (b) uniform temperature and (c) large gradient temperature.

When the cross-section is subjected to a non-uniform temperature profile, differential expansion occurs in each fibre and curvature is observed. Fig. 15 compares the beam mid-span deflection for the three cases. All curves have a similar pattern, but some points are noticeably different: at high temperatures, case $\mathrm{c}$ shows the lowest maximum deflection because the lower temperature in the top flange. Case $\mathrm{b}$ deflected faster, reaching the maximum deflection at $t=45 \mathrm{~min}$ that corresponds to the maximum temperature in whole cross-section; for case c, the bottom flange and the web reached the maximum temperature at $t=45 \mathrm{~min}$, but the maximum top flange temperature is only reached at $t=54 \mathrm{~min}$. During the cooling phase, for case $\mathrm{c}$ the bottom flange temperature decreased faster than the web and the top flange, leading to a faster reduction of deflection.

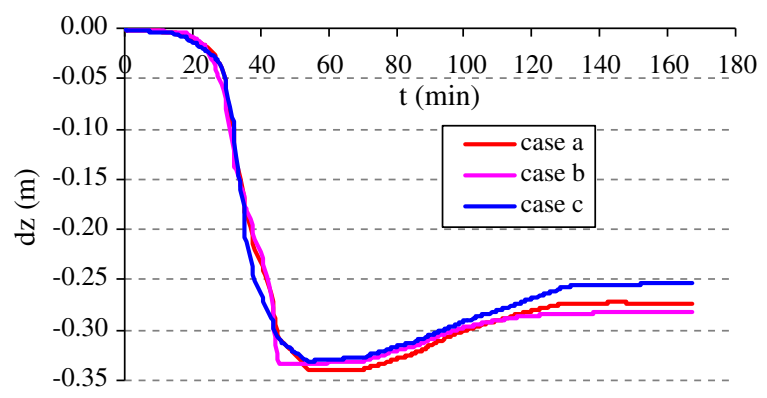

Fig. 15. Development of the mid-span deflection during the fire.
Although case $b$ showed the highest internal forces in the beam and is considered the critical thermal load for the design of steel members, the equivalent strain contours were softened around the joint area, while in the non-uniform temperature cases, large equivalent strains are concentrated in the lower zone of the beam, where the maximum temperatures are introduced.

\section{Influence of temperature gradient along the beam span}

Variations of temperature are usually only studied across the cross-section and it is assumed that the gradient temperature along the beam span is constant, EN 1993-1-2 [14]. Experimental observations show that due to the concentration of mass near the joints they exhibit different temperatures throughout the fire, Wald et al. [13]. In this study, the reference temperature (case a) was compared to a temperature gradient along the beam span that reproduces the measured joint temperatures (case b), as shown in Fig. 16.

Fig. 17 compares the mid-span deflection for both cases. A lowest maximum temperature $(10-15 \%)$ near the joint leads to a maximum displacement $15 \%$ lower than the reference case. During cooling, the recovery rate of deflection does not depend on the temperature gradient along the beam span. In contrast to what is observed for the midspan deflection, the influence of the gradient temperature along the beam is irrelevant on the internal forces along 

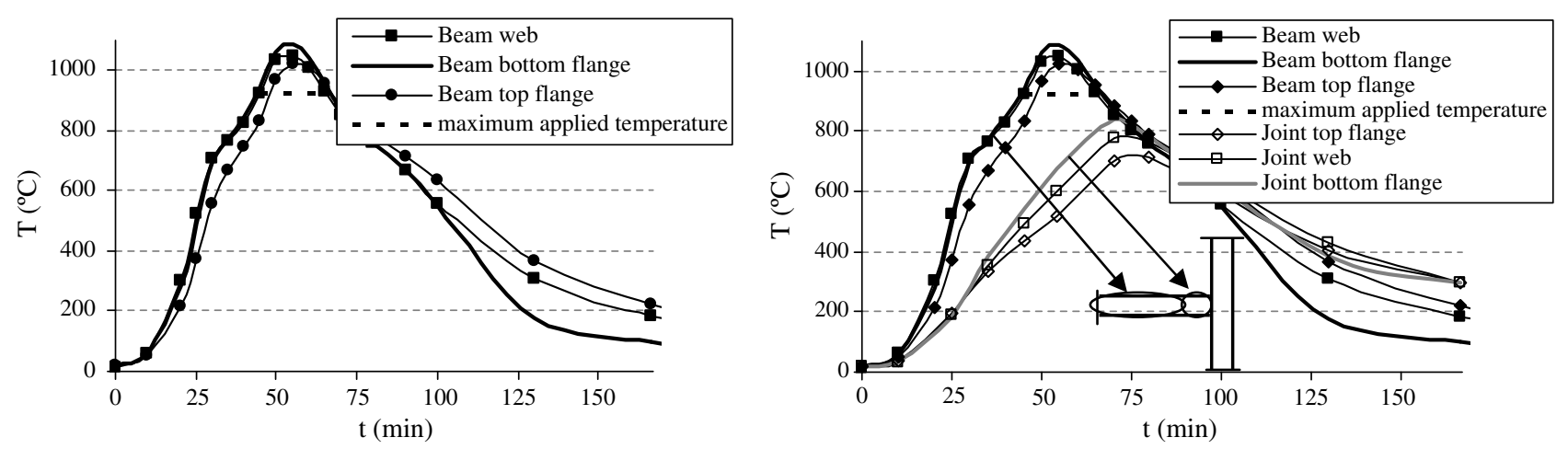

Fig. 16. Thermal loading: (a) reference case; (b) temperature gradient along the beam span.

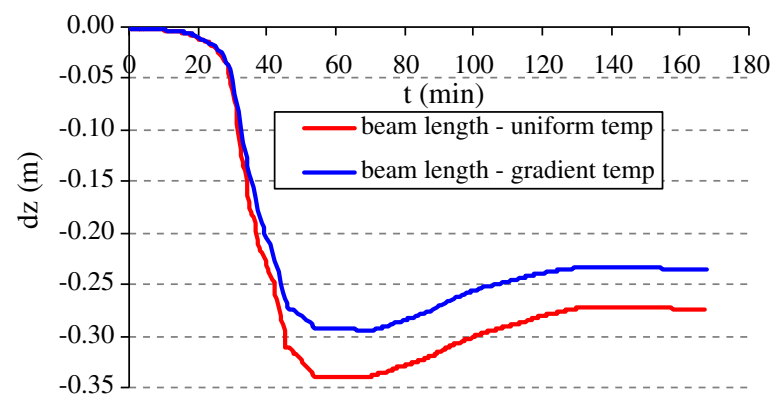

Fig. 17. Development of the mid-span deflection during the fire.

the beam. Small differences are observed during the cooling phase, because the temperature at the bottom flange of the joint decreased slower than the beam bottom flange, leading to a small increase of the sagging moment due to thermal bowing; although, the maximum strains are moved away from the joint.

\section{Effect of lateral restraints on the beam top flange}

Lateral torsional buckling is a relevant mode of failure for a steel beam at ambient and elevated temperatures. Under fire conditions a number of relevant research studies on the lateral torsional buckling of steel beams have been carried out. Bailey performed a numerical analysis for beams under a uniform temperature distribution [23]. Vila Real and Piloto conducted a few experiments of slender beams at uniform elevated temperatures [24] and Vila Real and Franssen [25] carried out a numerical study and proposed a design method for lateral torsional buckling of steel beam under uniform temperature, which has been adopted in the current version of EN 1993-1-2. This design method was improved by Vila Real et al. [26]. Recently, Yin and Wang presented a numerical study for beam laterally unrestrained with uniform and non-uniform temperature and different axial end restraints [8], in which some considerations about the axial reactions and mid-span deflection are also made.

In the following, lateral torsional buckling is discussed. Initial imperfections were the same for restrained and unre- strained beam (see Section 2.4). Fig. 18 compares the deformed mesh of the sub-structure restrained at the top flange with the evolution of the deformed mesh of the same model without lateral restraint.

At low temperatures, the beam behaviour is governed by thermal expansion only, and low vertical and lateral displacements are observed (Fig. 19). Approximately after $15 \mathrm{~min}$ the beam stiffness starts to decrease and an increase of lateral displacement without vertical displacements is observed. The axial force reduces (Fig. 20) as the beam deflects laterally and no local buckling near the joint is observed (Fig. 18). Due to the lateral movement of the unrestrained beam, the bending moment resistance is lower than for a beam with lateral restraints. Therefore, catenary action contributes more to the laterally unrestrained beam resistance. As the temperature increases, to the influence of catenary action is bigger than the bending and the lateral displacement of beam reduces so that the beam takes the original position while the large mid-span deflection is observed. Beyond this point, mid-span deflection is larger than the unrestrained beam (Fig. 19). The presence of lateral restraints delays the temperature at which the catenary action is achieved. At elevated temperatures, the lateral displacement is negligible, and a torsional failure mode is evidenced until the end of the fire (Fig. 18). The vertical deflection of both models converges during the cooling phase, reaching the same value at the end of the fire.

Fig. 21 compares the growth of bending moment against the fire evolution in the beam. At low temperatures, the bending moment development is similar in both cases. Bending moment starts to reduce as the beam starts to deflect laterally. Simultaneously, the lateral bending moment and the lateral rotation increase and reach maximum values at the instant corresponding to the maximum sagging moment of the restrained beam. The unrestrained beam reaches similar maximum lateral bending moment and maximum sagging bending moment. At elevated temperatures, the lateral bending moment reduces to negligible values and the hogging moment gets close to values similar to those observed on unrestrained beam. During the cooling phase, the lateral bending moment increases again. 
i)

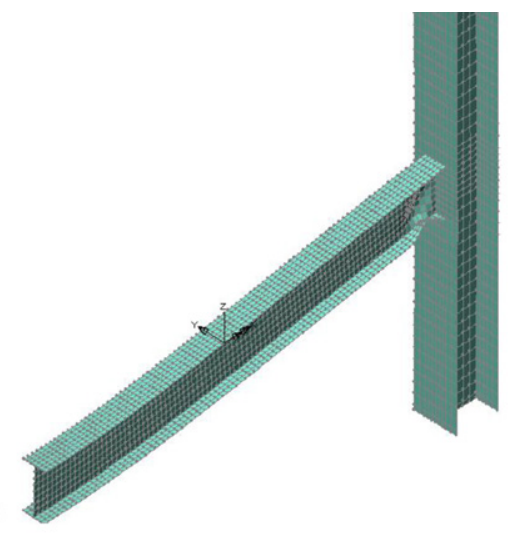

ii)

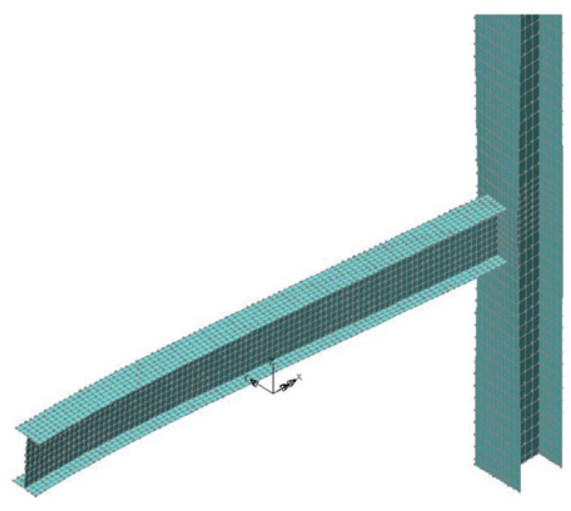

iv)

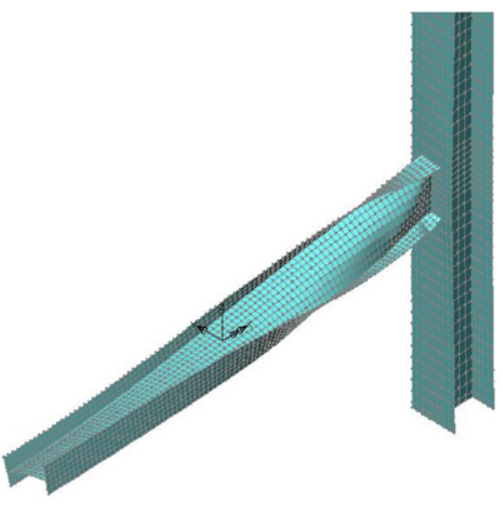

Fig. 18. Failure modes: (i) restrained beam; (ii) unrestrained beam (29 min.); (iii) unrestrained beam ( 36 min.); (iv) unrestrained beam (end of the fire $166 \mathrm{~min})$. Scale factor 1.0.

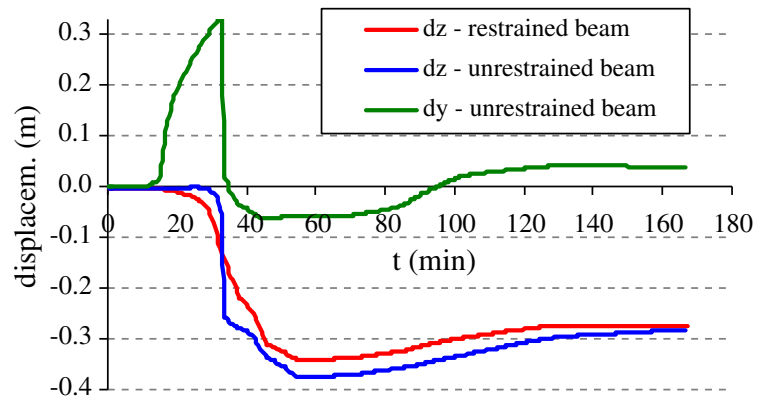

Fig. 19. Development of the mid-span deflection during the fire.

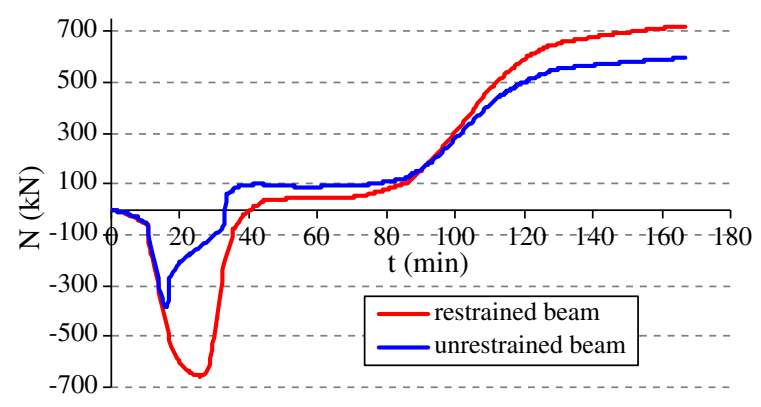

Fig. 20. Development of the beam axial force during the fire.

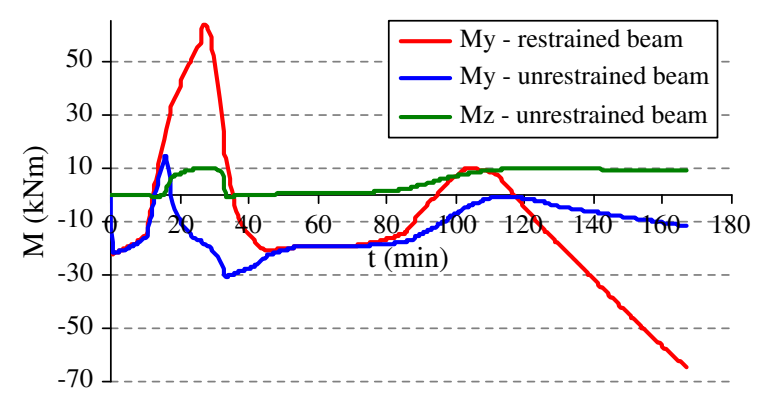

Fig. 21. Development of the joint bending moment during the fire.

\section{Effect of mechanical load factor}

In order to examine the effect of catenary action on the critical temperature of the beam, numerical simulations of restrained beams at different mechanical load levels were conducted by Liu [7] and Yin and Wang [8]. The results were compared to those obtained from experimental tests showing good agreement.

In this study, the reference case $\left(P_{\mathrm{fi}, \mathrm{d}}=20 \% P_{\mathrm{rd}}\right)$ was compared to four other cases: $P_{\mathrm{fi}, \mathrm{d}}=(12 \% ; 40 \% ; 60 \%$; $80 \%) P_{\text {rd }}$. 
Due to the large torsional deformations at high load levels, a nominal deformation failure criteria was accepted. The numerical failure is assumed when the cross-section rotation is larger than $90^{\circ}$. This failure condition was observed in the case of a mechanical load higher than $60 \% P_{\text {rd }}$ and occurred during the heating phase. As for the other cases, the failure modes are similar to those observed for the reference case.

The deflection curves for the five levels of loading are shown in Fig. 22. At low temperatures, beam deflection is dependent on the mechanical loading. A further rise in temperature leads to a progressive run-away of beam deflection as the loss of stiffness and strength accelerates; however, in the cases with low loading levels, the rate of run-way is reduced where the axial force is changing from compression to tension - catenary action (Fig. 23). In the cases with high loading levels, excessive deflection accompanied by torsional deformation is observed and the beam fails. As for the other cases, whenever the cooling phase is reached, the heated beam begins to recover strength and stiffness, together with a reduction of thermal strains which induces a reversal of the deflection. The rate of deflection reduction is not dependent on the mechanical load level.

Fig. 23 plots the growth of the axial force and bending moment against time for the five loading levels. Axial force curves have similar gradients up to a fairly similar maximum of compressive force, confirming that they have similar rates of thermal expansion irrespective of the applied

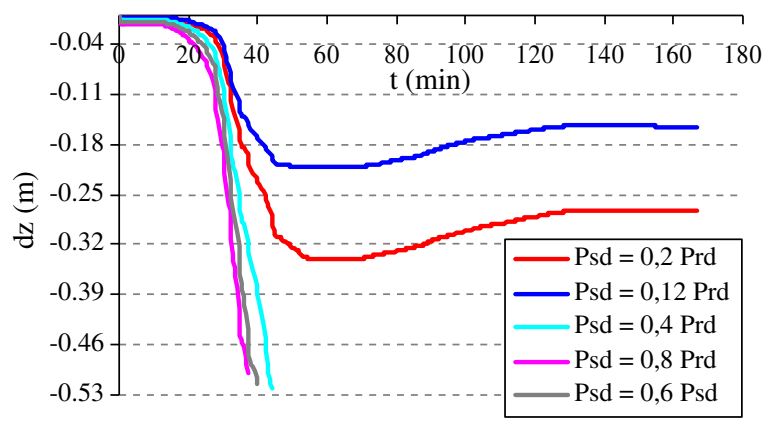

Fig. 22. Development of the mid-span deflection during the fire. load level. When the stiffness starts to decrease, lower compression forces at higher loading levels are observed. The compression force starts to decrease at a slightly lower temperature in cases with higher loading level. This is followed by the onset of the vertical deflection run-away. At high loading levels, the compressive force quickly changes to a tensile force and failure is attained due to excessive midspan deflection. At lower loading levels, the beam is supported by the catenary action which takes place earlier for beams with lower applied loading and a more obvious change of deflection gradient can be seen (Fig. 22). A higher tensile force at higher loading levels is reached. During the cooling phase, the heated beam recovers strength and stiffness and lower tensile forces at higher loading level are observed.

As the temperature increases, the bending moment also increases and the maximum bending moment is reached when the beam resistance started to decrease after $25 \mathrm{~min}$ at temperature of $400{ }^{\circ} \mathrm{C}$. The beams with high mechanical loading do not reach a sagging moment. Beyond that, the temperature continues to increase but the bending moment decreases until the room bending moment. In the cases where the beam failure is not observed before cooling, the bending moment and the rotation remain constant at high temperatures. The discontinuity of the bending moment curve due to the reversal thermal bowing during cooling is more noticeable in the high mechanical load cases. As the temperature continues to decrease to values below $500{ }^{\circ} \mathrm{C}$ the hogging moments have reversed. Residual effects are clearly very important in these cases.

The effect of the mechanical loading on the distribution of strains is similar to the effect of the beam span: maximum strains spread up in the cross-section as the mechanical loading increase. However, the high equivalent strains observed on the upper zone of the cross-section of short beams occurred because of the shear buckling of the beam web due to high compression in the beam, while the high values on the higher load factor cases result from the high tensile forces due to the large bending deformations. As the mechanical loading increases, the critical component moves from the bottom flange in compression to the top flange in tension.
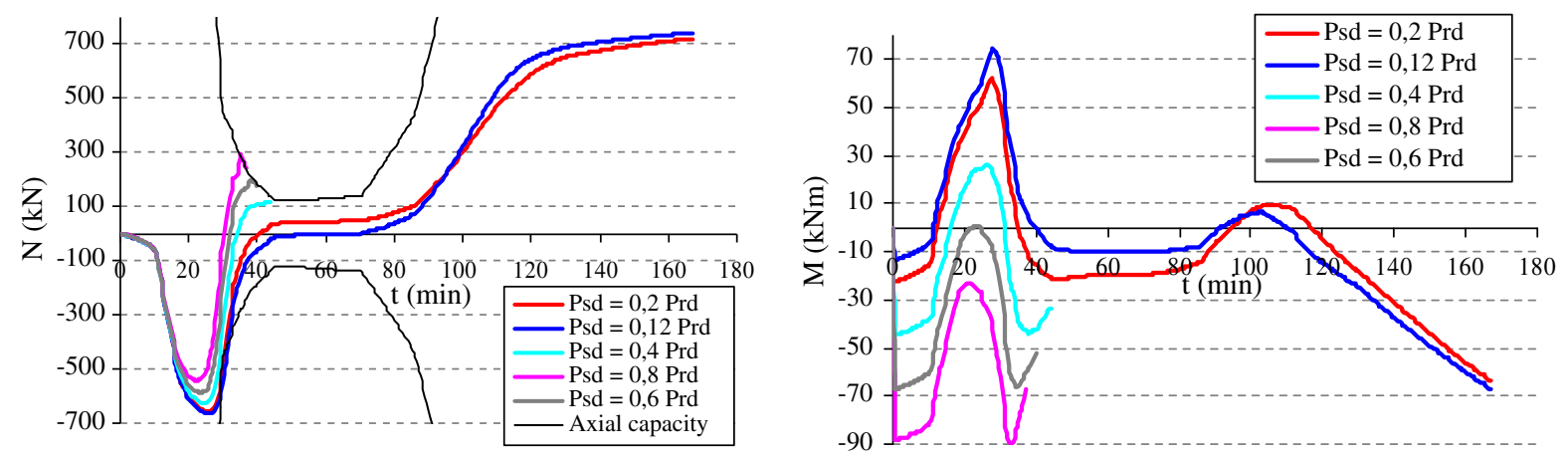

Fig. 23. Development of the beam axial force and joint bending moment during the fire. 


\section{Concluding remarks}

This paper presented the results of a numerical study using LUSAS, FE software package, to analyse the behaviour of a beam-to column steel system under fire. In order to provide credibility to the FE modelling results obtained by LUSAS they were compared to a fire dedicated program - SAFIR. A numerical parametric study was conducted to investigate possible behaviour of the sub-frame. In this way, insight into the behaviour of the steel girder, which is the most usual structural element of a floor in multi-storey buildings, exposed to natural fire is gained. The main characteristics of every particular failure modes that correspond to certain geometry of the girder are discussed in the text. The constant shape of the initial imperfections, consisting of the local and global imperfections, was used independently of the geometry of the girder. This approach is consistent with proposed implementation of initial imperfections according to EN 1993-1-5. In some cases, when clear discrepancy between the realistically assumed imperfections and the final failure mode exists, one should repeat the computation assuming the initial imperfection in a shape of the failure mode obtained in order to obtain the lower boundary of the fire resistance. However, in the cases considered in this paper, no reasons were found eligible to perform the additional analysis. There were no doubts about the finding that no fire protection is necessary for the composite girders exposed to the natural fire scenario, as measured in 7 th Cardington test. The parametric study also highlighted the influence of the end-restraints of the beam, thus indicating that behaviour is very much dependent of the joint characteristics and the degree of force redistribution that takes place as the fire progresses.

\section{Acknowledgement}

Financial support from the Portuguese Ministry of Science and High Education (Ministério da Ciência e do Ensino Superior) under FCT research project POCI/ $\mathrm{ECM} / 55783 / 2004$ is acknowledged.

\section{References}

[1] Simões da Silva L, Santiago A, Moore D, Vila Real P. Behaviour of steel joints under fire loading. Int $\mathbf{J}$ Steel Compos Struct 2005;5(6):485-513.

[2] Bradford MA. Elastic analysis of straight members at elevated temperatures. Adv Struct Eng 2006;9(5):611-8.

[3] Huang ZF, Tan KH, Ting SK. Structural response of a steel beam within a frame during a fire. In: Shen $\mathrm{ZY}$ et al., editors. Advances in steel structures; 2002. p. 1111-8.

[4] Santiago A, Simões da Silva L, Vila Real P. Effect of cooling on the behaviour of a steel beam under fire loading including the end joint response. In: Proceedings of ninth international conference on civil and structural engineering computing September 2-4, Nederlands: Egmond-aan-zee; 2003.
[5] Hao S, Usmani AS, Yang X, Zhang J. The effect of connections on fire resistance of axially restrained beams. In: Shen $\mathrm{ZY}$ et al., editors. Advances in steel structures; 2005. p. 1077-82.

[6] Liu TCM. Finite element modelling of behaviour of steel beams and connections in fire. J Construct Steel Res 1996;36(2):181-99.

[7] Liu TCM, Davies JM. Performance of steel beams at elevated temperatures under the effect of axial restraints. Int J Steel Compos Struct 2001;1(4):427-40.

[8] Yin YZ, Wang YC. A Numerical study of large deflection behaviour of restrained steel beams at elevated temperatures. J Construct Steel Res 2004;60:1029-47.

[9] Liu TCM, Fahad MK, Davies JM. Experimental investigation of behaviour of axially restrained steel beams in fire. J Construct Steel Res 2002;58:1219-30.

[10] Bailey CG, Burgess IW, Plank RJ. Analyses of the effects of cooling and fire spread on steel-framed buildings. Fire Safety J 1996;26:273-93.

[11] Wald F, Chladná M, Moore D, Santiago A, Lennon T. Temperature distribution in a full-scale steel framed building subject to a natural fire. Int J Steel Compos Struct 2006;6(2):159-82.

[12] Santiago A, Simões da Silva L, Vila Real P. Experimental investigation of the behaviour of a steel sub-frame under a natural fire. Document ECCS TC10-628, Trento, Italy; 2007.

[13] Wald F, Simões da Silva L, Moore DB, Lennon T, Chladná M, Santiago A, et al. Experimental behaviour of steel structure under natural fire. Fire Safety J 2006;41(7):509-22.

[14] European Committee for Standardization (CEN), EN 1993-1-2: 2005. Eurocode 3: design of steel structures. Part 1.2: general actions actions on structures exposed to fire, May 2005. Brussels: European Committee for Standardization (CEN); 2005.

[15] LUSAS 13. Theory manual. FEA Ltd., V.13.5. Surrey, UK; 2003.

[16] European Committee for Standardization (CEN). prEN 1090-2:2005. Execution of steel and aluminium structures - Part 2: technical requirements for the execution of steel structures. Brussels: European Committee for Standardization (CEN); 2005.

[17] Greiner R, Salzgeber G, Ofner R. New lateral-torsional buckling curves $\chi_{\mathrm{LT}}$-numerical simulations and design formulae. Document ECCS TC8-Report 30; 2000 [rev].

[18] Malvern LE. Introduction to the mechanics of a continuous medium. Englewood Cliffs, NJ: Prentice-Hall; 1969.

[19] Li G-Q, Yin Y-Z, Li M-F. Experimental studies on the material properties of high-strength bolt connection at elevated temperatures. Int J Steel Compos Struct 2002;2(4):247-58.

[20] Franssen J-M. SAFIR: a thermal/structural program modelling structures under fire. In: Proceedings NASCC 2003; 2003.

[21] British Standard Institute. BS 476: fire tests on building materials and structures, part 21: Methods for determination of the fire resistance of load-bearing elements of construction; 1987.

[22] Timoshenko SP, Goodier JN. Theory of elasticity. 3rd ed. Mc-GrawHill Book Company; 1970.

[23] Bailey CG, Burgess IW, Plank RJ. The lateral-torsional buckling of unrestrained beams in fire. J Construct Steel Res 1996;36(2):101-19.

[24] Vila Real P, Piloto P, Franssen J-M. A new proposal of a simple model for the lateral-torsional buckling of unrestrained steel I beams in case of fire: experimental and numerical validation. $\mathbf{J}$ Construct Steel Res 2003;59(2):179-99.

[25] Vila Real P, Franssen J-M. Numerical modelling of lateral buckling of steel I - beams under fire conditions - comparison with Eurocode 3. J Fire Protect Eng 2001;11(2):112-28.

[26] Vila Real P, Lopes N, Simões da Silva L, Franssen J-M. Lateraltorsional buckling of unrestrained steel beams under fire conditions: improvement of EC3 proposal. Comput. Struct. 2004;82(2021):1737-44. 